\title{
Personal Learning Environments and Online Classrooms: An Experience with University Students
}

\author{
Patricio Ricardo Humanante Ramos ${ }^{1}$, Francisco J. García-Peñalvo ${ }^{2}$, Miguel Ángel Conde-González ${ }^{3}$ \\ ${ }^{1}$ GRIAL Research Group \\ Faculty of Educational Sciences, Humanities and Technology \\ National University of Chimborazo, Ecuador \\ phumanante@unach.edu.ec
}

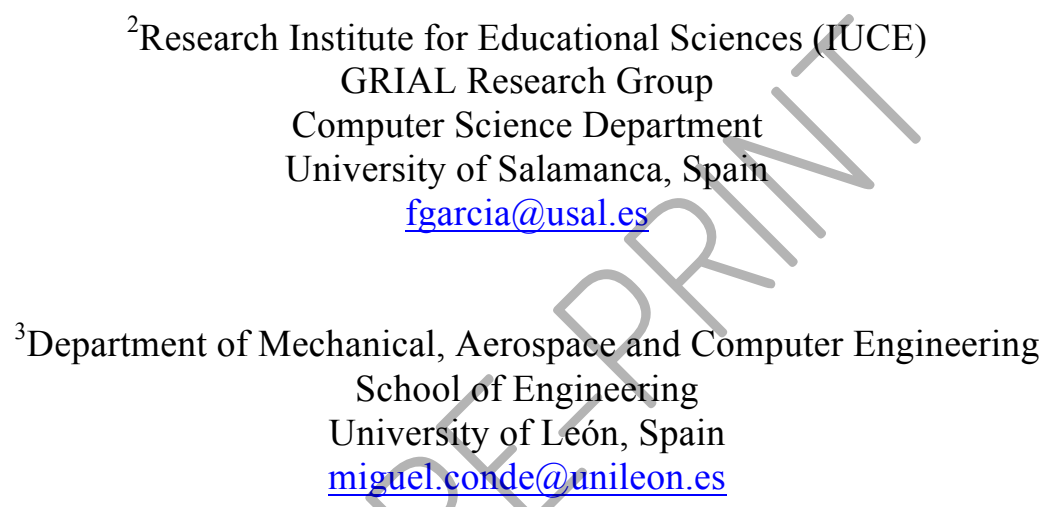

Abstract- The present study investigates the use of Learning Management Systems as tools constituting student's Personal
Learning Environments in the degree of Informatics Applied to Education in the National University of Chimborazo- Ecuador. The
main result of this work is that there is an increasing number of courses that rely on virtual classrooms, but learning occurs both in
and out of these learning environments. This study is the starting point for future research on the relevance, impact, and effectiveness
of incorporating Learning Management Systems in university teaching, as well as on relations and possibilities of integration between
them, Personal Learning environments, and mobile learning trends.

Index Terms - eLearning, Information and Communication Technology, Personal Learning Environments; Learning Management Systems; Higher Education; Virtual Classrooms.

\section{INTRODUCTION}

$\mathrm{T}$ he integration of Information and Communication Technologies (ICT) in the educational field has allowed the redesign of scenarios where the teaching and learning processes take place. This has caused a blurring of boundaries between face-toface, blended and online education and also between formal, non-formal and informal education [1]. According to this, the roles of teacher and student need to change [2]. This means a new revolution in the way we conceive learning experiences compared to the way it was done before [3].

It is important to point out that globally there is a massive incorporation of Learning Management Systems (LMS) platforms in the teaching practice [4]. For example, in Spain $91.78 \%$ of universities use both proprietary and open source platforms in their virtual campuses, where the open source platform Moodle is the most popular with 53.30\% of learning platform instances [5]. At the moment of preparation of this paper, Moodle website registers 53,562 sites and 68,852,768 users across 231 countries [6]. Thus, an increasingly widespread use of this platform has taken place throughout the world. On the other hand, there are studies that recommend its use due to different factors such as flexibility, support and continuous improvement [7]. Moreover, Moodle allows working with several teaching models [8], a very important functionality for the teacher in their role as mediator in the learning processes.

It is also known that learning has an individual dimension, because each person is unique, with his or her own interests, 
limitations and capabilities. Thus, each student requires a personalized process of knowledge acquisition process [9]. Therefore, there is a need to promote the so-called Personal Learning Environments (PLE), which can be understood as "the set of tools, data sources, connections and activities that each person uses assiduously to learn" [1]. In this regard, opportunities to enhance these learning spaces through the use of ICT appear.

Furthermore, at the National University of Chimborazo (a public institution of higher education located in Riobamba, a city localized $165 \mathrm{~km}$ south of Quito, the capital of Ecuador) the process of incorporating virtual teaching to classroom teaching began in 2009. Researchers and teachers of that university have established bLearning environments that combine traditional classes with the autonomous work of students mediated by technologies.

These new educational spaces, based on LMS, are mostly limited to the simple exposition of contents. Also, many of them lack clearly defined methods and specific strategies for this type of training [3]. This fact drives to wasting the potential that ICT provides, for example interaction and personalization.

Besides, it is known that formal education usually ends with the completion of the degree. However, people's learning process continues throughout their whole life [10-13], in order to increase their performance in professional contexts. They must be ready to face learning tasks at workplaces that in many cases are still nonexistent.

In the case of Informatics, this situation is more evident, because software solutions are continuously evolving. However, although students build mastery of certain tools, these may already be obsolete at the moment students begin to work in their professional practice. This means that they should work with new applications, programming languages, design tools, etc.

In light of the above, this paper is devoted to diagnosing the use of LMS as constitutive tools of students' PLE in the Informatics Applied to Education degree of Chimborazo National University in Ecuador. It is important to underline that these students enroll in their studies in the annual mode.

The rest of the paper is structured as follows. The theoretical foundation of this research is included in Section 2. The methodology appears in Section 3. In Section 4 the results are discussed and finally the conclusions are presented in Section 5.

\section{Personal Learning Environments}

The existence of a personal environment for learning is innate in humans, who are in a process of continuous learning and is maintained throughout their lives. These learning spaces are institutionalized, leading to what we call schooling, and direct responsibility for learning is attributed to it [14].

PLE have always been present in the history of mankind; however, with the massive adoption and incorporation of ICT in most daily activities, we are increasingly flooded with information. In other words learning is not centralized, but rather various types of items, resources, subjects, settings, etc. influence it.

The wide use of web 2.0 tools in education - particularly in the university - is a reality, also supported by the availability of connectivity and Internet access offered by today's electronic devices such as laptops, netbooks, tablets, smart phones, cameras and other electronics. These devices continuously include more and more functionalities, connectivity and storage possibilities.

At present, students access the contents (we refer to them as content because not all content is information [15]) in different ways and throughout several media: search engines, social networks, SMS, virtual classrooms, etc. This means alternative sources of information that are available to anyone, breaking also cultural and language barriers. However, these contents should be discussed, validated, curated and/or published [16].

Then, these new systems formed by all the resources, activities and elements present in today's education constitute the socalled PLE that, according to [2], is defined as:

"A learning environment centered on the users and customizable for them, which combines all those tools, services, opinions, people, resources and activities that are useful in the learning process. This environment must take into account the different forms of training, facilitates learning throughout the students' lives and allows the incorporation of new technologies. From a technological point of view, it can be defined as an integration framework that incorporates technologies 2.0, supports interaction with other learning contexts, facilitates integration and compatibility with existing systems (such as repositories and LMS) and provides systems for monitoring students as an evidence guide of the performed activity."

In the definition above, the PLE is even conceived outside the contexts that ICT may offer and it is extended to the social environment in which the person learns. Regarding technical features, it highlights the contribution of web 2.0 tools to the educational processes and the integration with other technologies and platforms that are present in the educational institutions and allow documenting the results of the learning processes.

\section{A. Basic Structure of a PLE}

According to Jordi Adell and Linda Castañeda's criterion [14], a basic PLE includes three types of tools and strategies: reading, reflection and communication (taking into account strategies in terms of mechanisms and activities). When we refer to the involved tools in each part of the PLE, we find those which are included in the so-called Web 2.0, as well as many free software alternatives that are currently available, either for installation on devices and computers, or from the cloud.

Furthermore, these authors defend that "There is neither tools nor strategies or mechanisms that can be considered unique to a single part of the PLE" [14], whereby one tool or resource could be exploited both to access information as well as to transform 
this information into knowledge through reflection. At the same time, the tool may provide spaces for socializing and sharing content, as for example with the use that can be given to documents in Google Drive, exposure and active participation in a videoconference or through blogs, to name some specific resources.

From a more technical perspective other authors propose a solution that emphasizes the interoperability and integration of different platforms [17-19]. Thus Conde-González states "PLE should be structured in services or in portable modular components that can be distributed at the whim of the user, which also allows adding new items" [20].

This broad view suggests accessibility and availability of resources, tools, activities and personal networks from different devices even outside the institutional environment [21-22] and promoting a user-centered learning. All of this is pursued with PLE, unlike a learning-centered institution in the case of the LMS [23].

\section{B. Infrastructure of a PLE}

Once the part of a PLE has been identified and the tools, mechanisms and activities that allow us to access, process and share learning have been defined, the elements constituting the infrastructure on which these environments are developed must be determined.

According to Casquero et al. [24], an ideal PLE would provide students with one-way access to all the services they use and, once inside, the technological scenarios would be also unique, in order to ensure the learning personalization. This is now possible thanks to some technologies such as content syndication via RSS (Really Simple Syndication), which are formats for sharing content on the Web. This allows students to select only the most interesting topics for them, of which they will receive continuous updates. Similarly, each student's PLE may be a new information channel available for subscription.

The contents in these environments may be structured in three types of content management systems: blogs, wikis and LMS [25], because they allow publishing, building and updating information, since any change they produce will automatically be reflected in the PLE through notifications. In addition, the contents could be complemented with other specific digital resources such as linked pages, files, images, photographs, videos, audios, documents and presentations, i.e. the same resources that are housed in specific locations such as Delicious for markers, Flickr for images, YouTube for videos, Slideshare for presentations and Scribd for documents [14], as well as the online archives offered by Google Drive.

Regarding the needed relationships for the suitable information flows within these environments, the network infrastructure needed to support a PLE should include nodes, connections between nodes and digital resources (learn-streaming). The nodes may be by the digital identity of each student and the connections between them would be established by both academic and private interests [24].

\section{Integration with LMS}

These personal learning environments should be developed and enhanced for all educational levels. However, this study is contextualized specifically in higher edueation, in which the students have a specific technological resource that is now present in most higher education institutions, such as virtual classrooms managed through the institutional LMS [5].

The scientific literature shows some proposals of LMS and PLE integrations [26-29], thanks to some possible scenarios [30].

1) LMS and the existence of a PLE in paratlel. This is the current way in which learning is carried out. On the one hand, students have access to a virtual space in the LMS for each subject. In these spaces they manage their learning activities, have access to their resources, tasks, interactions, assessments and so on. However, it is also true that the students use other resources outside these formal or institutional environments just in order to access other resources, process information and communicate with their peers, i.e. we may consider these non-formal virtual environments as their PLE. Nevertheless, if we want to have a real PLE in the higher education students' context, it is not possible to have a complete independence between the institutional LMS and each student's PLE, because the virtual learning spaces managed by the LMS are a fundamental part of the students' personal learning process and therefore must be present in their PLE [20].

2) Opening the LMS through the inclusion of web services and interoperability initiatives. In this second scenario, the LMS should be accessible from other tools included in the students' PLE. However the main barriers are the lack of openness in the design of the institutional platforms to be accessed by third parties and, on the other hand, the fact that those initiatives are focused on information exportation and not on interaction exchange. That is to say, communication is oriented in one direction, from the LMS towards the external tools; basically exchanging information about what happens on the platform and providing no information or interaction back to the LMS.

3) Integration of external tools in the LMS. In this integration model, the selection of tools, which would be part of the PLE, comes from the LMS managers, who are responsible for designing and administering them, limiting in this way the students' freedom for choosing their own resources, for example the inclusion of social networks like Twitter in the LMS.

It is important to emphasize that the successful integration of the LMS in the PLE will be related to the flexibility, transparency and facility offered to both teacher and student, taking advantage of the potential that these new technological approaches offer, and ensuring the application of these new educational contexts centered on the student [20,23]. 


\section{Methodology}

This research is based on a quantitative approach which belongs to a non-experimental study because it is developed without the deliberate manipulation of variables, and the phenomena are only observed in their natural environment to be analyzed afterwards [31]. Also, it is transversal or transactional because the data collection process is performed in a unique moment, and it is descriptive because it will investigate the use of LMS as constitutive tools of PLE in a group of university students.

The students of the Informatics Applied to Education degree in the National University of Chimborazo (Ecuador) (UNACH) who are enrolled in the annual mode form the population of this research. It is noteworthy that this degree is in the midst of a change process, from annual to biannual, although at the time of developing this study the third and fourth years of the annual modality are in force, with an academic period from September to July. We have chosen the annual modality due to the fact that, at the date of application of the instrument, the students have been working with virtual classrooms for a significant time (since September 2012), allowing more objective opinions - unlike courses in the biannual mode that have recently started the new academic year.

Enrolled students, who attend classes regularly in the academic year September 2012 - July 2013, are shown in Table I. Also, due to the small size of the group, we may consider the whole population.

The instrument used in this study is a questionnaire that included 19 items, based on the information collection documents submitted by Conde-González [20] from which we have tried to adapt the questions to the terminology used in the context of university Ecuadorian and according to the specialty of the students surveyed.

It has also included questions about accessing mobile devices and how the students see the LMS is managing their learning processes. This instrument was implemented using Google Docs forms and applied online.

TABLE II

ARE CONTENTS (DOCUMENTS, PRESENTATIONS) AVAILABLE IN VIRTUAL CLASSROOMS ENOUGH?

TABLE I

NUMBER OF STUDENTS ATTENDING REGULARLY ENROLLED IN THE ANUAL MODE 2012-2013. SOURCE UNACH.

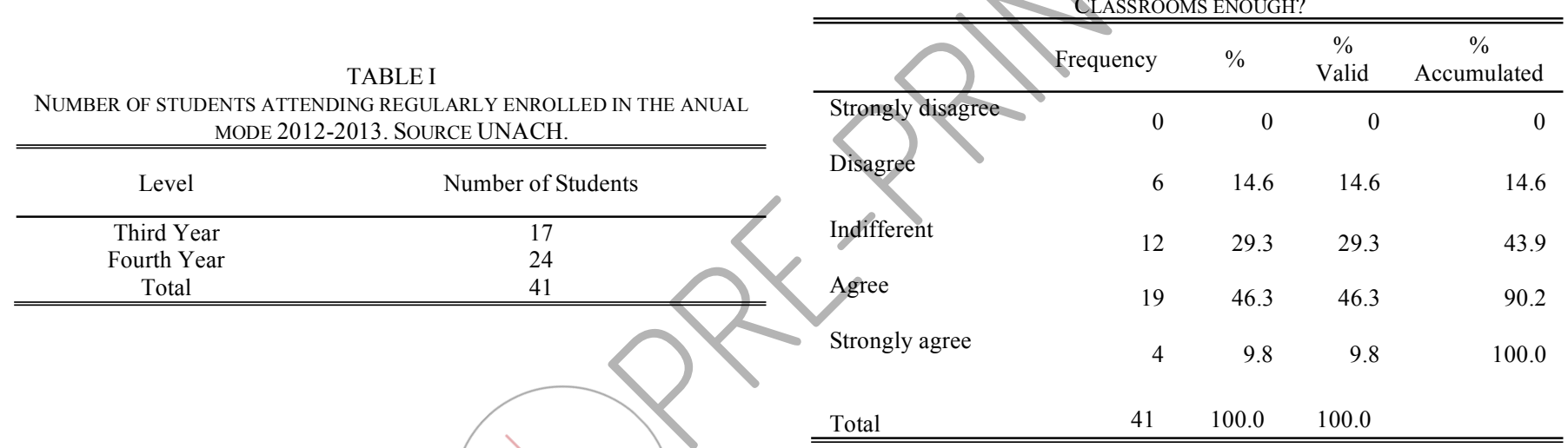

\section{A. About the tools to access information}

In this section we are interested in knowing the appraisal that students give of the virtual classrooms as means of access to information and whether this access is made through other resources too.

Thus, only $14.6 \%$ disagree that there are enough contents (documents, presentations) available in virtual classrooms, while most do agree that these resources are enough $(46.3 \%)$. If the data are deeply analyzed, no student answered that they strongly disagreed, while $9.8 \%$ strongly agreed. It is also important to mention that $29.3 \%$ are indifferent to this question. We can see these results in Table II.

Also, we want to know if they accessed all of the available resources. More than half of the respondents (51.2\%) agreed that they accessed all available resources, one third of the respondents to this question were indifferent and a cumulative percentage of $12.2 \%$ said they did not access all that was published in the virtual classrooms.

On the other hand, there are obviously other online electronic media that students use in their learning. $87.8 \%$ of cumulative answers show students agree or strongly agree regarding the use of other online tools to review information about course topics -resources that are not found within virtual classrooms (Youtube, Wikipedia, forums, Slideshare, etc.).

Figure 1 summarizes the respondents' opinions in this category of questions.

\section{B. About the tools for edition and publication of information}

Currently, there are many web 2.0 tools that allow editing and publishing documents, presentations and multimedia resources; these resources are available from the cloud, and require only a registration through an email account to use and publish. This section of questions inquires about the adoption of these tools in the group of surveyed students. 
It should be noted that over $50 \%$ of respondents ( $56.1 \%$ cumulative) only use programs installed on their computer for editing contents. One out of three respondents ( $31.7 \%$ cumulative) disagrees or strongly disagrees with this statement, which suggests that this group of students are using online tools for editing documents, presentations, videos, images, etc.

With regard to the question about what resources students use for publishing the developed content, $24.4 \%$ disagree and $7.3 \%$ strongly disagree that the online platform is the only medium where they publish their content. However, more than half of the respondents, which corresponds to $51.2 \%$ cumulative, say that they only socialize their work through the tasks, wikis, glossaries and forums of the institutional LMS.

However, students do not publish their content only through the LMS: they do so through other online resources. In this case three out of every four students (75.6\% cumulative) say they agree and strongly agree on using online tools for editing and publishing contents (documents, presentations, videos and images), which are not offered within LMS (Google Docs, Blogger, WordPress, YouTube, Flickr, SlideShare, Scribd, etc.), while only $9.8 \%$ of students think otherwise. Figure 2 summarizes the opinions of respondents in this category of questions.

\section{About the tools for relationship and communication}

This group of questions deals with the resources that students use for their communication, where over $50 \%$ of surveyed students (51.2\% cumulative) use channels like chat, messaging and forums of the institutional LMS only for academic purposes. In contrast, only $9.8 \%$ of the respondents strongly disagreed with this statement.

Moreover, about half of the respondents ( $48.8 \%$ cumulative) believe that the reason for using the forums of the virtual classroom is that they are mandatory. A smaller percentage of respondents $(31.7 \%)$ participate in these communication channels without obligation, which suggests this functionality is important for this learning process.

For $82.9 \%$ (cumulative) of the students surveyed, it is very important to use social networks, chat, forums, and other types of online resources as media for academic purposes (given that $51.2 \%$ of the respondents agree with the statement and $31.7 \%$ strongly agree with it) while only two respondents do not share this statement. This suggests that this small group of students does not mix their online social spaces with their academic activities. Figure 3 is a summary of the opinions of respondents in this category of questions.

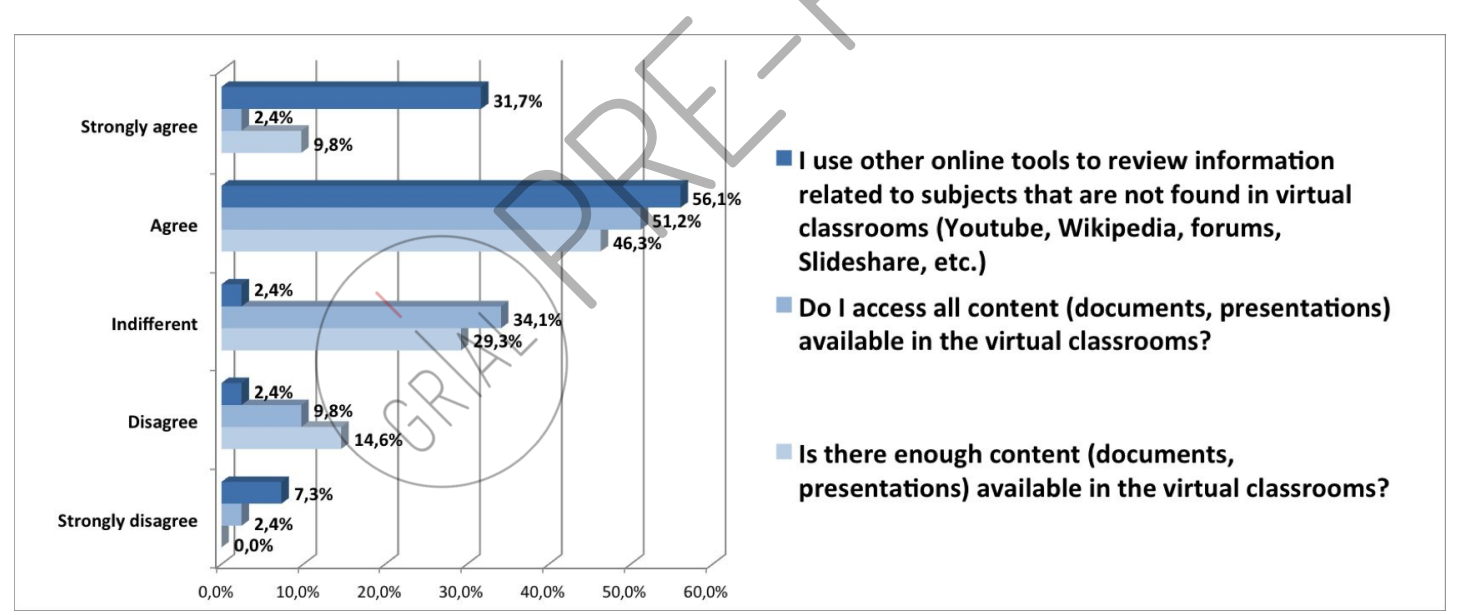

Figure 1.- Tools for information access $(\mathrm{n}=41)$ 


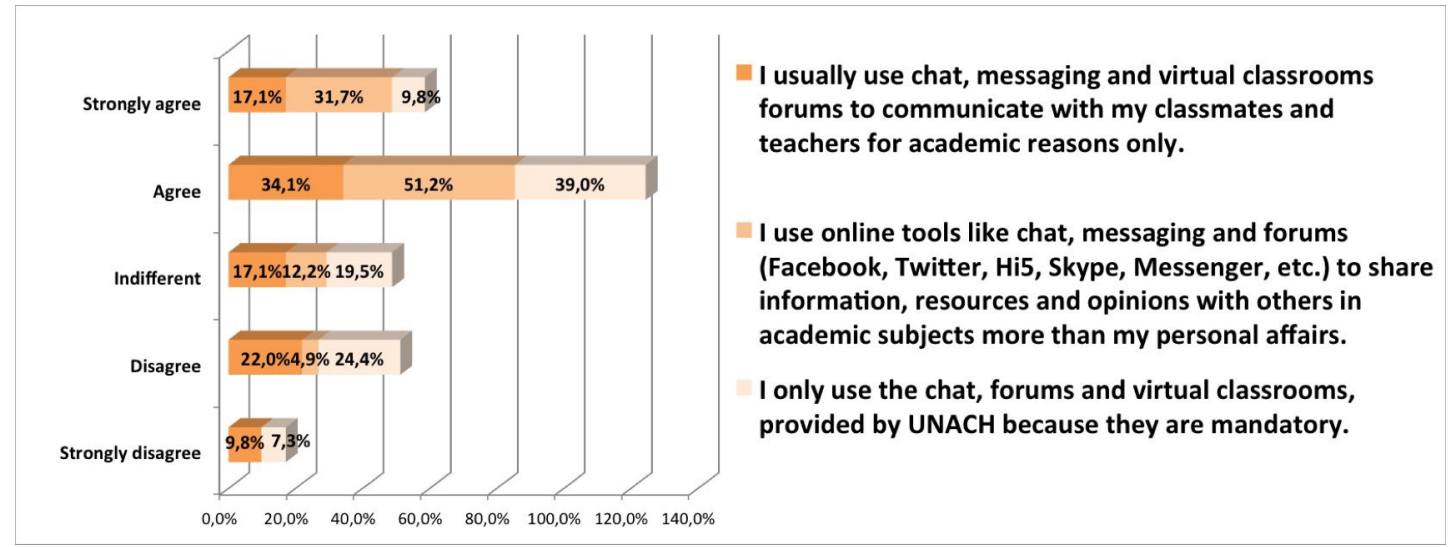

Figure 3.- Tools for relationship and communication $(n=41)$
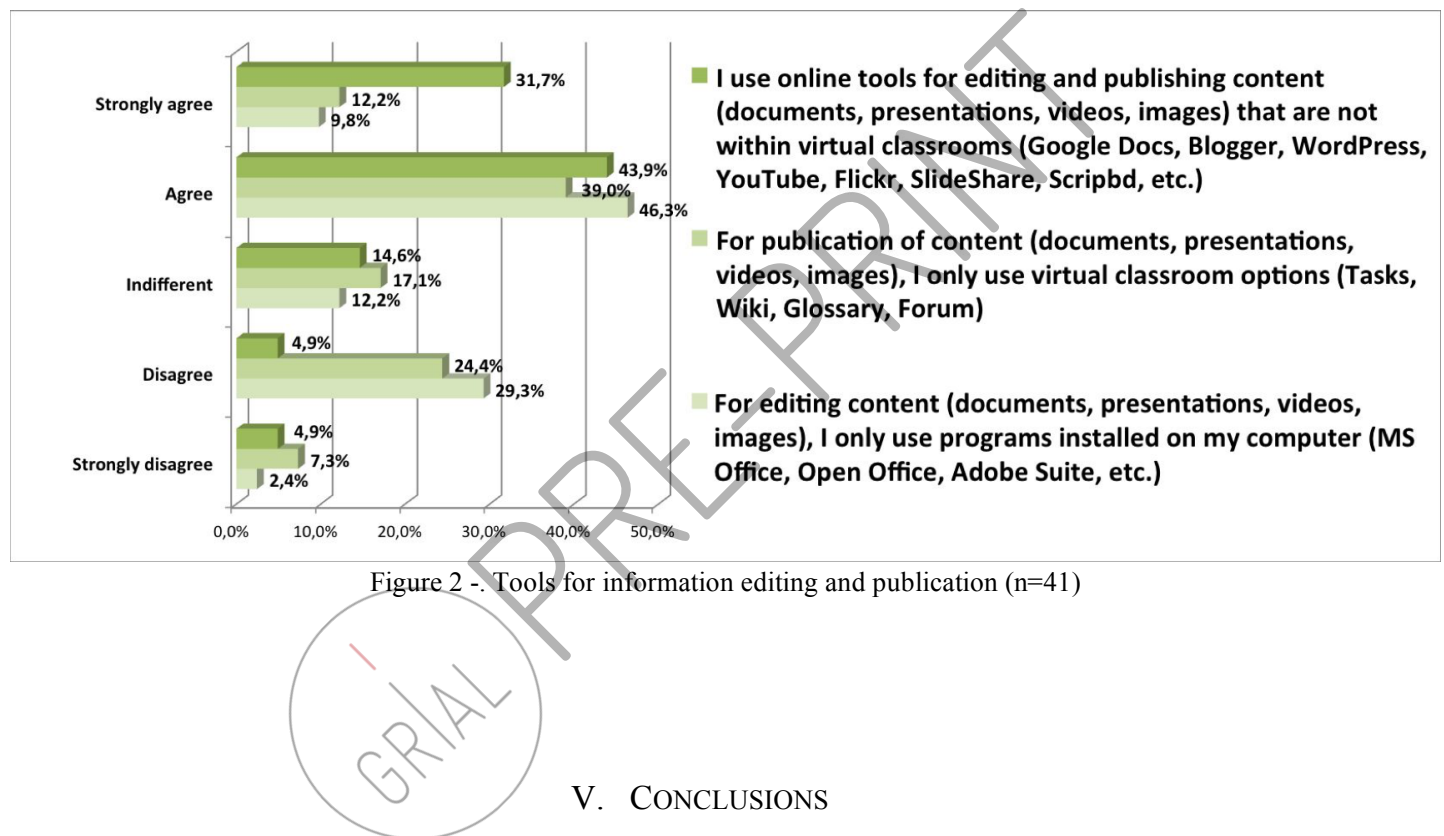

Some important conclusions can be drawn from this study, although because of the nature of the investigation they cannot be generalized.

However, this opens up important research lines in the field of ICT applied in teaching and learning processes at the National University of Chimborazo.

Regarding the use of virtual classrooms in the institutional LMS, although $39 \%$ of students polled in this study take advantage of virtual spaces for activities outside the academic context, most of them (61\%) state that the use given to these virtual spaces is strictly academic. This invites to raise questions in the future about the effectiveness of this practice, the impact on academic performance, the quality of learning and motivation in educational processes.

The resources published in the LMS are considered to be enough for more than $50 \%$ of the surveyed students, although they do not use all available resources; besides, they rely on other online tools (YouTube, Wikipedia, forums, Slideshare, etc.) to review information related to the subjects.

Most of students use desktop programs to do their tasks. These are socialized through virtual classrooms, but the use of online tools for editing and publishing content is also evident.

LMS communication tools offered to students are mostly used for strictly academic purposes, inclusive; the participation in forums and chats is not natural to all of them, but it responds to extrinsic motivation seen as obligation. This could be due to the fact that a large number of respondents $(82.9 \%)$ use other online resources such as social networking for academic activities.

Regarding the use of LMS functionalities as constitutive tools of the surveyed students' PLE, we can say that these virtual education scenarios allow accessing, editing and publishing much of the academic information. They also allow providing functionalities for communication and relationships with others. However, other external tools are used as well, so it is 
concluded that the institutional LMS is an important part but not enough to structure the students' PLE.

Furthermore, most of the respondents believe that the institutional LMS only manages their learning processes partially, because of other learning activities occurring outside the institutional context. The criterion in the group is divided in order to consider if this extra effort should be taken into account for the subjects' evaluation. However, there is a shared agreement (95.1\%) on the possibility of integrating web 2.0 tools in virtual classrooms, which might become a big challenge for future projects of innovation and integration of ICT in learning processes.

It should also be noted that a great part of the surveyed students (73.2\%) consider the mobile access to LMS functionalities and web 2.0 tools as an aid to their learning processes, which makes us think that in a near future the number of students who have or have access to a mobile device will increase. This percentage in the present study is only $22 \%$ of the surveyed students.

Finally, we are convinced that learning activities should be designed to promote the use, development and consolidation of the PLE and so take advantage of the continuous innovations in the field of ICT applied in educational processes.

\section{ACKNOWLEDGMENTS}

We would like to thank the Ministry of Science and Innovation of the Spanish Government for funding the project under identification number TIN2010-21695-C02-01, and the Regional Council of Education of Junta de Castilla y León (Spain) through the projects GR47 and MPLE (ref. SA294A12-2).

Similarly, we want to thank the Ministry of Higher Education, Science, Technology and Innovation of the Government of Ecuador (SENESCYT) and National University of Chimborazo (UNACH) for funding to perform this research.

This research work is made within University of Salamanca PhD Programme on Education in the Knowledge Society scope.

\section{REFERENCES}

[1] J. Adell and L. Castañeda, "Los Entornos Personales de Aprendizaje (PLEs): una nueva manera de entender el aprendizaje," in Claves para la investigación en innovación y calidad educativas. La integración de las Tecnologías de la Información y la Comunicación y la Interculturalidad en las aulas. Stumenti di ricerca per l'innovaziones e la qualità in ámbito educativo. La Tecnologie dell'informazione e della Comunicaziones e l'interculturalità nella scuola., R. Roig Vila and M. Fiorucci, Eds., ed Alcoy, Spain: Marfil-Roma TRE Universita degli studi, 2010.

[2] J. Salinas, "Algunas perspectivas de los entornos personales de aprendizaje," in TICEMUR 2008, Lorca (MU), 2008.

[3] F. J. García-Peñalvo, Advances in E-Learning: Experiences and Methodologies. London: IGI Global, 2008.

[4] F. J. García-Peñalvo, "Docencia," in Libro Blanco de la Universidad Digital 2010, J. Laviña Orueta and L. Mengual Pavón, Eds., ed Barcelona, España: Ariel, 2010, pp. 29-61.

[5] M. P. Prendes, "PLATAFORMAS DE CAMPUS VIRTUAL CON HERRAMIENTAS DE SOFTWAREs LIBRE: Análisis comparativo de la situación actual en las universidades españolas," Murcia, 2009.

[6] Moodle, "Moodle Statistics," Moodle, 2014. [Online]. Available: https://moodle.org/stats/. [Accessed: 27-November-2014].

[7] J. Adell, J. Castellet, and J. Gumbau, "Selección de un entorno virtual de enseñanza/aprendizaje de código fuente abierto para la Universitat Jaume I," presented at the Castellón de la Plana: Centre d'Educació i Noves Tecnologies (CENT) de la Universitat Jaume I, Castellón, 2004.

[8] P. Baumgartner, "Cómo elegir una herramienta de gestión de contenido en función de un modelo de aprendizaje," Open Education Europa, 17-May2005. [Online]. Available: http://www.openeducationeuropa.eu/es/article/C $\% \mathrm{C} 3 \% \mathrm{~B} 3$ mo-elegir-una-herramienta-de-gesti\%C3\%B3n-de-contenido-enfunci\%C3\%B3n-de-un-modelo-de-aprendizaje. [Accessed: 02-Feb-2014].

[9] A. Berlanga and F. J. García-Peñalyo, "IMS LD reusable elements for adaptive learning designs," Journal of Interactive Media in Education, vol. 11, 2005 .

[10] J. Field, Lifelong Learning and the New Educational Order. Trentham Books, 2006.

[11] Leibowicz, Ante el imperativo del aprendizâje permanente, estrategias de formación continua. CINTEFOR, 2000.

[12] F. J. García-Peñalvo, R. Colomo-Palacios, and M. D. Lytras, "Informal learning in work environments: training with the Social Web in the workplace," Behaviour \& Information Technology, vol. 31, pp. 753-755, 2012.

[13] F. J. García-Peñalvo, M. Á. Conde, V. Zangrando, A. García-Holgado, A. M. Seoane, M. A. Forment, et al., "TRAILER project (Tagging, recognition, acknowledgment of informal learning experiences). A Methodology to make visible learners' informal learning activities to the institutions," Journal of Universal Computer Science, vol. 19, p. 1661, 2013

[14] L. Castañeda and J. Adell, "La anatomía de los PLEs," in Entornos Personales de Aprendizaje: Claves para el ecosistema educativo en red, L. Castañeda \& J. Adell., Alcoy: Marfil, 2013, pp. 11-27.

[15] A. Brey, D. Innerarity, and G. Mayos, La sociedad de la ignorancia y otros ensayos. Barcelona : Infonomia, 2009.

[16] A. J. Berlanga, F. J. García-Peñalvo, and P.B. Sloep, “Towards eLearning 2.0 University,” Interactive Learning Environments, vol. 18, no.3, pp. 199-201, 2010.

[17] M. Alier Forment, M. J. Casany Guerrero, M. Á. Conde González, F. J. García-Peñalvo, and C. Severance, "Interoperability for LMS: the missing piece to become the common place for e-learning innovation," International Journal of Knowledge and Learning (IJKL), vol. 6, pp. 130-141, 2010.

[18] M. Á. Conde-González, F. J. García-Peñalvo, and M. Alier, "Interoperability scenarios to measure informal learning carried out in PLEs," in Proceedings of the Third IEEE International Conference on Intelligent Networking and Collaborative Systems, IEEE INCoS 2011 F. Xhafa, L. Barolli, and M. Köppen, Eds., ed Los Alamitos, CA, USA: IEEE CS Press, 2011, pp. 801-806.

[19] F. J. García-Peñalvo, M. Á. Conde-González, M. Alier, and R. Colomo-Palacios, "A case study for measuring Informal Learning in PLEs," International Journal of Emerging Technologies in Learning (iJET), vol. 9, pp. 47-55, 2014

[20] M. Á. Conde-González, "Personalización del aprendizaje: Framework de servicios para la integración de aplicaciones online en los sistemas de gestión del aprendizaje," PhD Thesis. 03-Oct-2012. [Online]. Available: http://www.tesisenred.net/handle/10803/84752. [Accessed: 23-Jan-2014].

[21] F. J. García-Peñalvo, M. Á. Conde, and A. D. Pozo, “A Mobile Personal Learning Environment Approach,” in Virtual, Augmented and Mixed Reality. Systems and Applications, R. Shumaker, Ed. Springer Berlin Heidelberg, 2013, pp. 132-141.

[22] F. J. García-Peñalvo and M. Á. Conde, "The impact of a mobile Personal Learning Environment in different educational contexts," Universal Access in the Information Society, vol. 14, 2015.

[23] S. Leone, Characterisation of a Personal Learning Environment as a Lifelong Learning Tool. New York: Springer, 2013.

[24] O. Casquero, J. Portillo, R. Ovelar, M. Benito, and J. Romo, "iPLE Network: an integrated eLearning 2.0 architecture from a university's perspective," Interact. Learn. Environ., vol. 18, no. 3, pp. 293-308, 2010. 
[25] O. Casquero, "PLE: Una perspectiva tecnológica," in Entornos personalizados de aprendizaje: Claves para el ecosistema educativo en red, L. Castañeda and J. Adell, Eds., ed Alicante: España: Marfil, 2013, pp. 71-84.

[26] F. J. García-Peñalvo, M. Á. Conde, M. Alier, and M. J. Casany, "Opening learning management systems to personal learning environments," J. Univers. Comput. Sci., vol. 17, no. 9, pp. 1222-1240, 2011 .

[27] L. Moccozet, "Introducing learning performance in personal learning environments," in Proceedings of the 12th IEEE International Conference on Advanced Learning Technologies, ICALT 2012, 2012, pp. 702-703.

[28] R. Kop and H. Foumier, "Developing a framework for research on personal learning environments," ELearning Pap., vol. 35, 2013.

[29] M. Á. Conde, F. J. García-Peñalvo, M. Alier, E. Mayol, and C. Fernández-Llamas, "Implementation and design of a service-based framework to integrate personal and institutional learning environments," Science of Computer Programming, vol. 88, pp. 41-53, 2014.

[30] S. Wilson, O. Liber, M. Johnson, P. Beauvoir, P. Sharples, and C. Milligan, "Personal Learning Environments: Challenging the dominant design of educational systems," J. E-Learn. Knowl. Soc. - Engl. Version, vol. 3, no. 2, pp. 27-38, Nov. 2009.

[31] R. Hernández, C. Fernández, and P. Baptista, Metodología de la investigación. México DF: McGrawHill, 2010.

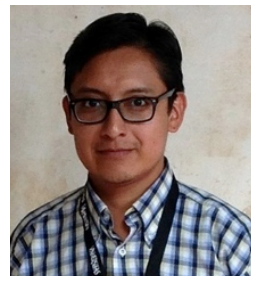

Patricio Ricardo Humanante Ramos completed his undergraduate studies Systems Engineering at the Polytechnic School of Chimborazo, his master studies at the National University of Chimborazo and the University of Salamanca. He has worked as a professor at the National University of Chimborazo (UNACH) since 1999 and is currently writing his thesis in the PhD program "Education in the Knowledge Society" in the University of Salamanca, as scholarship holder of the National Secretary of Higher Education, Science, Technology and Innovation of Ecuador (SENESCYT). His main research interests are related to E-Learning, the Development of Educational Software and the Informatics Applied to Education.

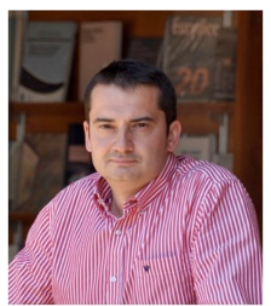

Francisco José García-Peñalvo did his undergraduate studies in Informatics at the University of Salamanca and University of Valladolid and his Ph.D. at the University of Salamanca. Dr. García-Peñalvo is the head of research group GRIAL (Research Group Interaction and eLearning). His main research interests focus on eLearning, Computers \& Education, Adaptive Systems, Web Engineering, Semantic Web and Software Reuse. He has led and participated in over 50 research and innovation projects. He was Vice Chancellor Innovation at the University of Salamanca between March 2007 and December 2009. He has published more than 300 articles in international journals and conferences. He has been guest editor of several special issues of international journals (Online Information Review, Computers in Human Behaviour, Interactive Learning Environments...). He is also a member of the program committee of several international conferences and reviewer for several international journals.

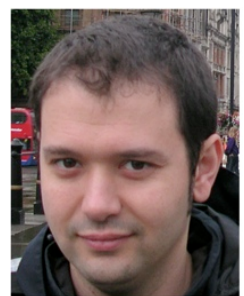

Miguel Ángel Conde-González did his undergraduate studies in Engineering in Informatics at the University of Salamanca and a PhD in the same university in 2012. From 2002 to 2004 he worked in the field of education, imparting different computer courses. In 2004 was in the software development for GPM, a company of multimedia and web development. In 2005 he began working for Clay, International Formation in the department of $\mathrm{R}+\mathrm{D}+\mathrm{i}$, where he was involved in various projects for eLearning. From 2007 to 2012 he was associate teacher at the University of Salamanca, where he has also worked as researcher of group GRIAL. In 2013 he worked as associate teacher at the University of León and has been linked to projects of Service of Informatics at this university since then. He is currently working as Professor Assistant at the University of León. His thesis and his research focus on how to merge and exploit experiences of formal learning, informal and non-formal. He has published over 100 articles on the field of eLearning including books, book chapters, journals and national and international conferences.

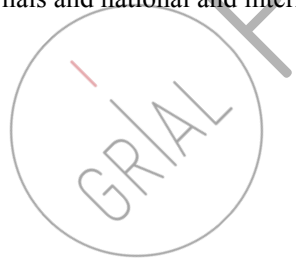

